\section{Time wearing orthosis in the management of chronic low back pain : preliminary study of the impact on the functional parameters.}

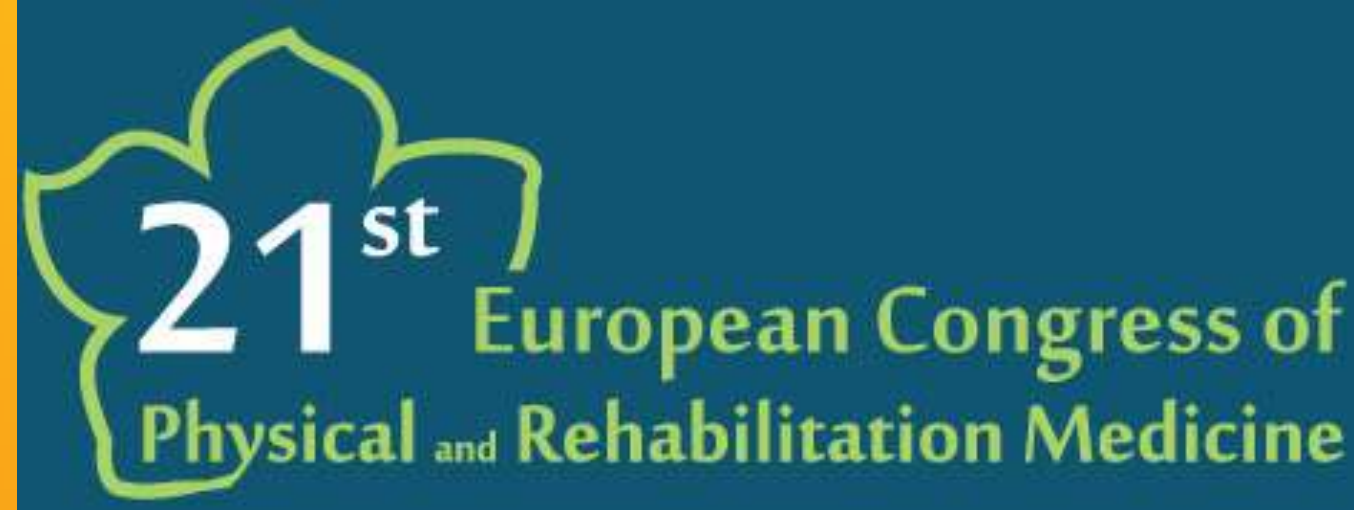

Alexandre SCHMIT, Laurence HAVE

Department of Physical Medicine and Rehabilitation of the Desgenettes Army Training Hospital

\section{Introduction:}

The use of a thoraco-lumbo-sacral orthosis (TLSO) is a classical tool in the management of chronic low back pain patients.

But there is now evidence or strong consensus on the modalities about the duration of time wearing TLSO

It seems pertinent to evaluate the impact of the duration of application of the rigid orthosis on the clinical evolution through the various algo-functional scores commonly used.

\section{Objectives:}

To evaluate the influence of orthotic wear time on the evolution of algo-functional parameters of chronic low back pain.

How is it possible to evaluate the wearing time of a rigid lumbar orthosis ?

Several types of recording devices ${ }^{1}$ of the time wearing thoraco-lumbar orthosis are found in the literature.

The main ones are represented by an embedded data recording device associated with a module for detecting the port of the orthosis.

We differentiate :

A detection of a pressure force 2,3 (with a pressure button or force sensor type FSR Force Sensitive Resistor) which has the advantage of being simple to use but unreliable and costly because it does not exist properly (the device must be made specifically for the study)

- A detection of the surface temperature ${ }^{4,5}$ at the internal part of the orthosis in contact with the patient. We choose this second solution and presented a preliminary study of 5 patients.

\section{Material and methods :}

\section{1) Patients:}

Patients included in this study are drawn from a cohort of patients treated in the Department of Physical Medicine and Rehabilitation of the Desgenettes Army Training Hospital between January 15t, 2017 and January 1st, 2018. Inclusion criteria included: chronic low back pain, exclusion of red flags, achievement of the whole rehabilitation program, namely: the implementation of three months of a rigid orthosis, multidisciplinary hospital management of two or three weeks with physiotherapy, occupational therapy, psychomotricity, balneotherapy, nutritional management and analgesic tools.

\section{2) Functionnal scores:}

Classical functional scores were used before and after wearing the orthosis : Visual Analog Scale, Quebec, Dallas, Fear Avoidance Belief Questionnaire, and Hospital Anxiety Depression Scale.

\section{3) Time recording device:}

Observance was assessed using an ELITECH ${ }^{\circledR}$ RC-4 data logger with external sensor. Each device is attached to the posterior part of the TLSO, protected by a box inaccessible to the patien and the external sensor was buried at the level of the waist and directly in contact with the patient.

\section{4) Data management:}

The data were extracted with ELITECH ${ }^{\circledR}$ RC-4 software, and managed by Matlab® software. We considered the start of monitoring at the first day of wearing orthosis and the last one at the first day of the hospitalization.

All ELITECH ${ }^{\circledR}$ RC-4 data logger were adjusted to record one temperature every fifteen minutes. The data were sampled by minute with Matlab® software.

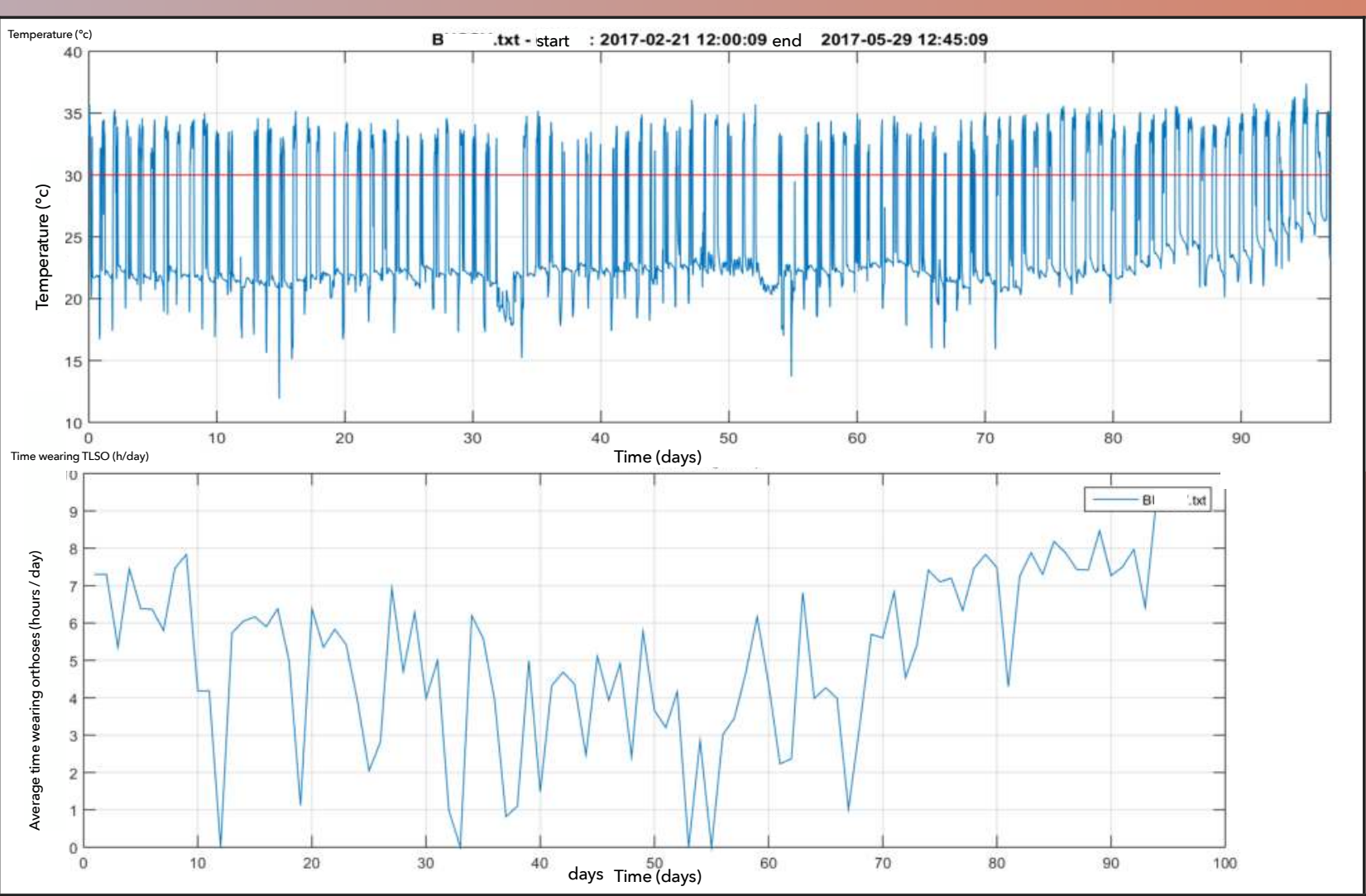

\section{Results:}

For each patient we thus recorded a curve of surface temperature at the level of the internal and posterolateral part of the rigid orthosis.

The detection threshold is set at $30^{\circ} \mathrm{C}$ as is commonly accepted in the literature.

It is possible to measure precisely the time during which the external sensor registers a temperature higher than $30^{\circ} \mathrm{C}$

The time wearing orthosis recorded was between 23 to $821 \mathrm{~h}(2,1 \%$ to $74,9 \%$ of total recommended time of $1096 \mathrm{~h}$ ).

All the patient had a favorable evolution during their reeducation with a significative decrease of their VAS greater for the patients who wore the orthosis for the longest time $(p=0,05)$

There were no significant modification of the HADS by the orthosis (anxiety $p=0,368$, depression $p=0,067)$.

The Quebec score was more significantly increased for the patients who has the longest time wearing
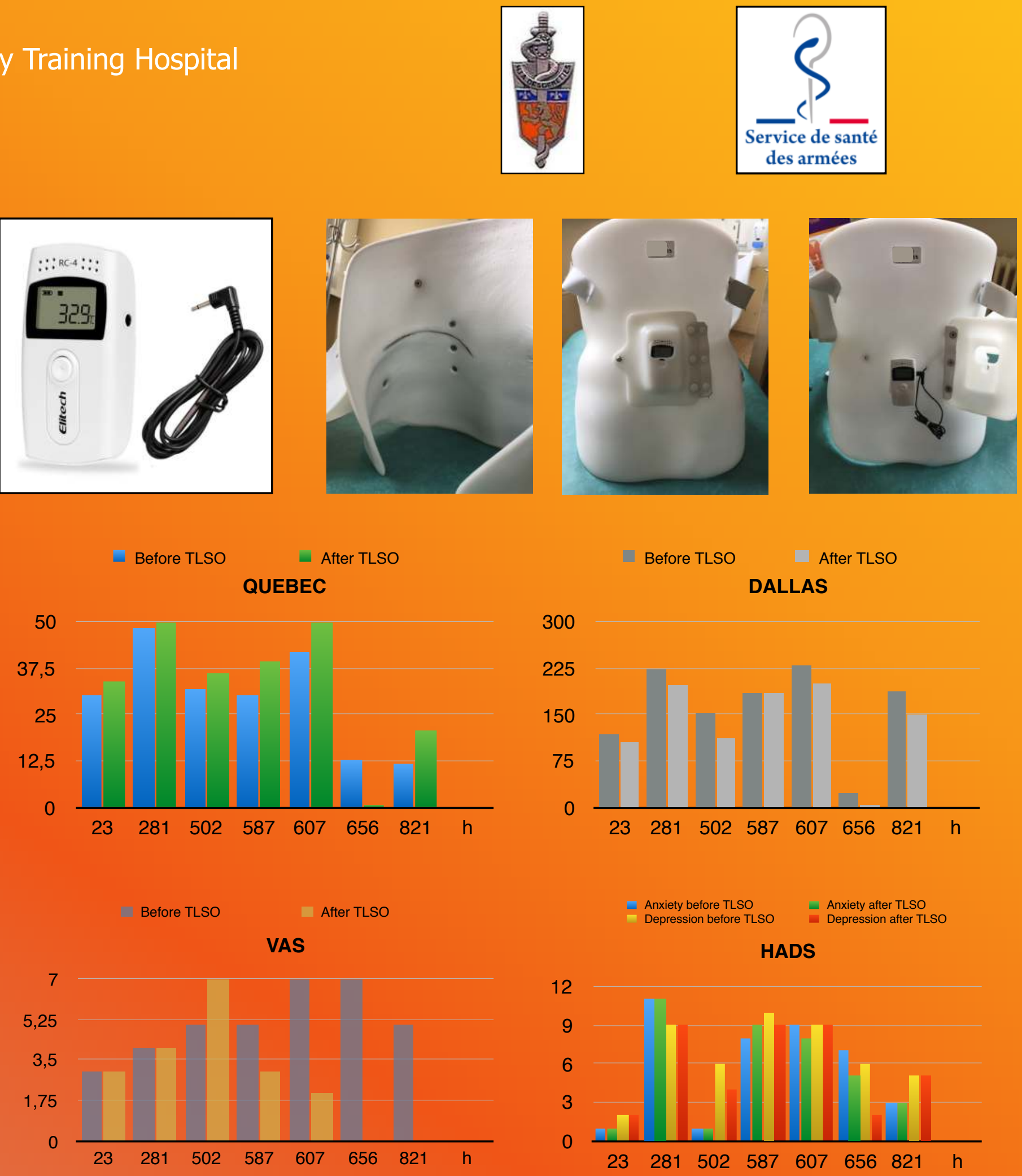

HADS

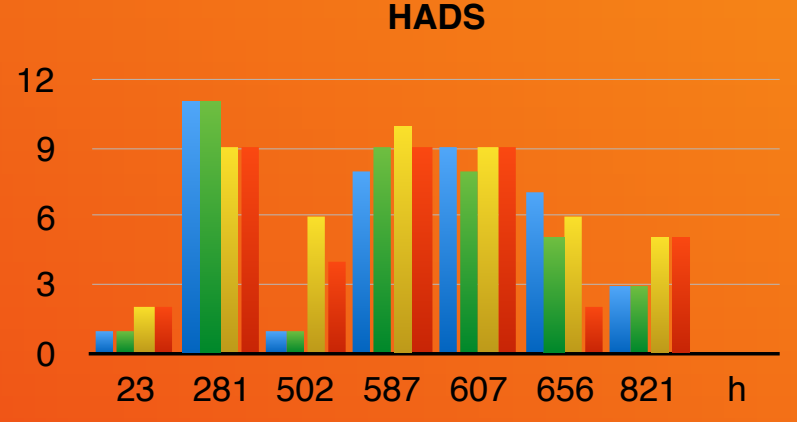

FABQ1 before TLSO FABQ1 after TLSO $\quad$ FABQ2 before TLSO $\quad$ FABQ2 after TLSO

FABQ

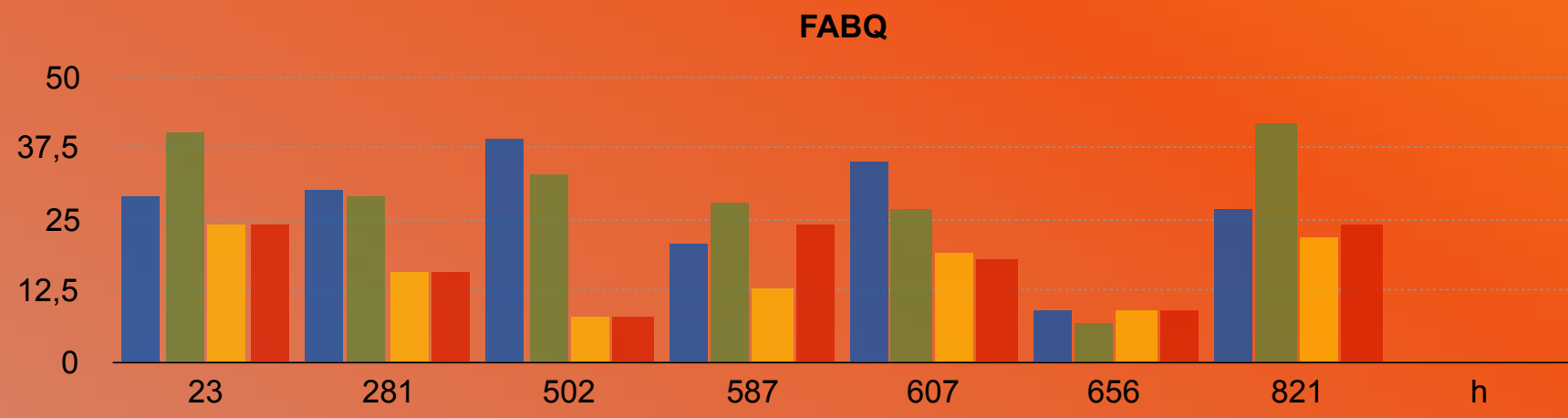

\section{Discussion:}

The recording of temperature seems to be a simple way to assess the duration of wearing a rigid orthosis. It is inexpensive, has a large recording capacity (up to 16,000 measurements) and a two year autonomy. Its accuracy is good with a thermal resolution of $0.1^{\circ} \mathrm{C}$, and a thermal inertia of $0,45^{\circ} \mathrm{C} / \mathrm{min}$ at implementation and $0,36^{\circ} \mathrm{C} / \mathrm{min}$ threshold of $30^{\circ} \mathrm{C}$ and the aspect of the curve.

The data collected allow to validate the impact of wearing time of the rigid orthosis on the evolution of clinical parameters in chronic low back pain, in particular as regards the algo-functional scores.

This method of monitoring the wearing time orthosis has the avantage to evaluate and optimize the observance of a TLSO, which is an important point of the success in the reeducation of a low back pain patient.

We can note that our patient knew that their observance was observed and the best time was only $56,2 \%$. It would be probably the consequence of the period of static seated position during which the TLSO was poorly tolerated.

Most patients describe in routine a discomfort in front of the TLSO with compression points on the inguinal folds or the stomach (with repercussion during meals).

The decreased of the VAS suggests that effectiveness of the orthosis on pain is related to the wearing time

The increase in the Quebec score in proportion to the duration of wearing, confirms the impact of the rigid device on the acts of daily life. Patients are probably more impacted by the brace than the pain.

\section{Conclusion:}

A precise and reliable measurement of the wearing time of the rigid orthosis is essential for the study of the impact of this on the functional parameters in chronic low back pain.

The device for recording the temperature at the orthosis is therefore simple, reliable and reproducible.

\section{References:}

1- Thatipelli, Sneha, Anupama Arun, Philip Chung, Mozzivar Etemadi, James Alex Heller, Dillon Kwiat, Jill Imamura-Ching, Michael R. Harrison, et Shuvo
« Review of Existing Brace Adherence Monitoring Methods to Assess Adherence »: Journal of Prosthetics and Orthotics $28, n^{\circ} 4$ (octobre 2016): 126-35.

2 - Lou, Edmond, Doug Hill, Douglas Hedden, Jim Mahood, Marc Moreau, et Jim Raso. «An Objective Measurement of Brace Usage for the Treatment
Adolescent Iddiopathic Scoliosis ». Medical Engineering \& Physics 33, no 3 (avril 2011): 290-94. 3 - Havey, Robert, Thomas Gavin, Avinash Patwardhan, Steven Pawelczak, Kamal Ibrahim,
Method for Measuring Orthosis Wearing Time S Spine 27, $^{\circ} 2$ (15 janvier 2002): 211-14

4- Benish, Brian M., Kristin J. Smith, et Michael H. Schwartz. « Validation of a Miniature Thermochron for Monitoring Thoracolumbosacral Orthosis Wear Time
Spine 37 , no 4 (féverier 2012): S309-15.

5- Hunter, Louis N., Mitell Sison-Wiliamson, Melissa M. Mendoza, Craig M. McDonald, Fred Molitor, M. J. Mulcahey, Randal R. Betz, Lawrence C. Vogel, et Anita
Bagley. «The Validity of Compliance Monitors to Assess Wearing Time of Thoracic-Lumbar-Sacral Orthoses in Children with Spinal Cord Injury ». Spine 33, n $^{\circ} 14$ 